\title{
how many extra people should london be planning for?
}

Tony Champion looks at why the ONS population projections for London released in May indicate a considerably lower increase than its previous set did two years ago, discusses how much faith should be placed in the latest figures, and points to consequent uncertainty about the rate of growth in other parts of the country

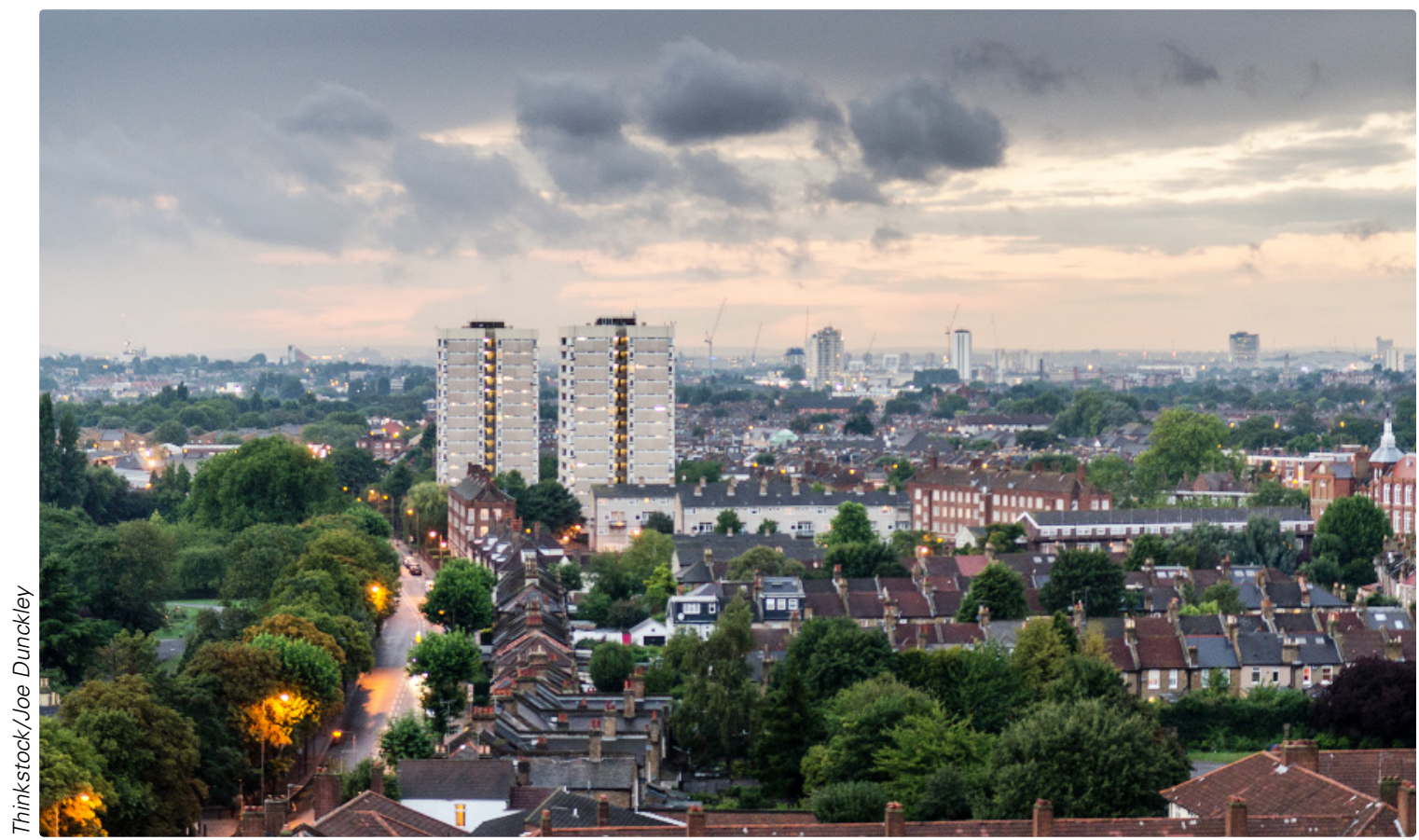

The latest ONS population projections suggest a much smaller rise in London's population compared with its previous set two years ago

If 'a week is a long time in politics', as famously uttered by Harold Wilson in 1964, then certainly two years would appear to be a long time in demography and planning. The official sub-national projections for England released two years ago indicated that London's population would be 10.96 million in 2039 , 
whereas the figure in the new projections for 2041 released by the Office for National Statistics (ONS) in May is 10.35 million. This is a substantial change with potentially important consequences for the draft new London Plan, which is predicated on the figure of 10.78 million for $2041 .^{2}$ Also, to the extent that the change reflects altered assumptions about migration in and out of the capital, there are implications for other parts of the country. The aim in this article is to provide more information about these projections so as to try to help planners decide how best to react.

To set the context, our starting point is provided by Table 1, which gives the population totals for London, defined as the Greater London Authority (GLA) area and statistical region, and for good measure includes the 2012-based projections data as well as those for the two subsequent (2014-based and 2016-based) sets. The table covers the full 25-year projection period for each one, running to 2037, 2039 and 2041, respectively, and also gives the figures for the other sets' start and end years as appropriate in order to get a better handle on the differences between them.

The key features of this table are the following. The last but one line reiterates the big drop in London's projected growth expected for the full 25year projection period between the 2014-based and latest set, down by some 860,000 people, whereas between the 2012- and 2014-based series the 25year growth number had been raised, albeit only by some 80,000. Meanwhile, the table's bottom line shows the growth expected for the 21-year period covered by all three projections, with the first indicating that London's population in 2037 would be 1.90 million higher than in 2016, the second putting the increase just a bit larger at 1.99 million, but the latest set reducing this to 1.37 million, a cutback of over 600,000 or $31 \%$.

How these changes have come about can partly be understood by reference to the upper parts of the table. It looks as if between 2012 and 2014 things developed pretty much on target, with the 8.54 million starting population for the 2014-based set being only marginally above the 8.53 million projected by the 2012-based set for 2014. Even by 2037, the new projection of 10.82 million was only $1.5 \%$ larger than the 10.66 million given by the 2012based series.

In that context, the difference between the 2014based and the latest projections is in marked contrast, not only in scale but also because the trend is in the opposite direction. Part of the explanation for this can be seen to lie in the latter's starting population in 2016 being below what was projected for then by the 2014-based set, which in turn can be put down to two factors. One is a real slowdown in London's overall growth over these two years. The other arises from recent changes in ONS methodology that in combination have resulted in a downward revision of the estimate of London's starting population in 2016. Both of these changes have then fed through into the numbers projected forward to 2041 and now give just a 50,000 a year increase towards the end of this

\section{Table 1}

\section{London's population as projected by the latest three official population projection series}

\begin{tabular}{|c|c|c|c|}
\hline \multirow[t]{2}{*}{ Year } & \multicolumn{3}{|c|}{ Population } \\
\hline & $\begin{array}{c}\text { 2012-based } \\
\text { thousands }\end{array}$ & $\begin{array}{c}\text { 2014-based } \\
\text { thousands }\end{array}$ & $\begin{array}{c}\text { 2016-based } \\
\text { thousands }\end{array}$ \\
\hline
\end{tabular}

$2012 \quad \mathbf{8 , 3 0 8}$

2014

8,531

\section{8,539}

2016

8,759

8,832

8,770

2037

10,662

10,820

10,142

2039

10,976

10,245

2041

10,346

\section{Change}

Full 25 years

2,354

2,437

1,576

2016-37

1,903

1,988

1,372

Source: Calculated from ONS data. The starting-year population estimates are in bold, whereas the other figures are projections or calculations derived from these. Each number is rounded to the nearest thousand, so the change data may not sum exactly 
Table 2

Comparison of the 2014-based and the 2016-based projections of London's population change for the decade 2016-26, by demographic component - annual average

\begin{tabular}{lccc}
\hline $\begin{array}{l}\text { Component } \\
\text { of change }\end{array}$ & $\begin{array}{c}\text { 2014-based } \\
\text { thousands }\end{array}$ & $\begin{array}{c}\text { 2016-based } \\
\text { thousands }\end{array}$ & $\begin{array}{c}\text { Difference } \\
\text { thousands }\end{array}$ \\
\cline { 2 - 4 } & 139.0 & 127.9 & -11.2 \\
\hline Births & 48.5 & 50.8 & +2.3 \\
Deaths & +90.5 & +77.1 & -13.5 \\
Natural change & 180.7 & 171.4 & -9.4 \\
International immigration & 101.6 & 95.9 & -5.7 \\
International emigration & +79.1 & +75.4 & -3.7 \\
Net international migration & & & -4.1 \\
In-migration from UK & 211.6 & 207.5 & +7.0 \\
Out-migration to UK & 276.1 & 283.1 & -11.1 \\
Net within-UK & -64.5 & -75.6 & -14.8 \\
Net all migration & +14.6 & -0.2 & -28.3 \\
Sum of all components & & & +76.9 \\
\hline Source: Cals & +105.2 & & \\
\hline
\end{tabular}

Source: Calculated from ONS data. Numbers may not sum exactly because of rounding

period, rather than the 75,000 annual increase indicated by the 2014-based set.

What lies behind the changes between the two latest sets of projections can best be explained by reference to the four main demographic components of change - namely births, deaths, international migration, and internal (within-UK) migration. For this purpose, we narrow down the focus to the first ten years covered by the 2016-based projections, as this is of most immediate interest for planning policy, and compare this with the same ten years of numbers from the 2014-based series, namely 2016-26. The numbers, including the difference between the two sets, are expressed as annual averages across the decade.

The results, as shown in Table 2, are very clear. All four main components of demographic change contribute to the lowering of London's projected population growth for 2016-26. Compared with the 2014-based series for this decade, births are down, deaths are up, there will be less net immigration from abroad, and London's net migration loss to the rest of the UK is now expected to be greater.

Of the total cutback in projected growth by some 28,300 a year over this decade, the largest element is the reduction in expected number of births, by 11,200 a year. This is closely followed by the $11,100-$ a-year reduction in within-UK migration balance, the latter being due both to more people leaving London and to fewer moving to it. Net immigration from abroad comes next, with a drop of 3,700 a year from 2014-based expectations, with the smaller number of arrivals in the latest projections only partially offset by the drop in departures. The smallest change from the 2014-based series is the 2,300-a-year increase in the number of deaths projected for the decade.

This leads on to thinking about what lies behind these changes, which all act negatively on London's projected rate of population growth compared with the 2014-based series - as well as posing questions about how much confidence can be placed in the revised set of assumptions responsible for them.

Starting with the number of deaths, this is the component of change about which there has traditionally been the greatest certainty about future trends. Over the last 40 years mortality rates nationally for both men and women have fallen consistently, down by $53 \%$ and $45 \%$, respectively since 1976. Since around 2011, however, there has been little or no improvement in mortality rates, ${ }^{3}$ which has forced the ONS to make a judgement on whether this is merely a short-term blip or a real change of trajectory. As evidence has been mounting 
in favour of the latter, the ONS and its expert panel have trimmed life expectancy in 2041 by a full year, dropping the figure for males from 84.6 to 83.6 years and that for females from 87.4 to 86.4 years. ${ }^{4}$ These are the figures for England as a whole, but the scale of the reduction will be very similar across the country, including London.

Turning to the 11,200-a-year reduction in the projected number of births for London for 2016-26, the main explanation can again be found in the national level projections. Basically, recent trends suggest that women will be having fewer children in future than was believed when the 2014-based projections were being prepared. For England, the total fertility rate (broadly the average number of births per woman) was put at 1.90 then, but this has now been reduced to 1.85 .

In addition, in the case of births there is a further place-specific factor helping to reduce the total number of births expected - namely the difference from the 2014-based projections in the size and composition of London's population. Slower overall population growth than previously expected means fewer potential mothers. This impact of this is compounded by the effect of the changes in migration between the two sets of projections shown in Table 2. With the inflow to London being dominated by $16-29$ year olds, a reduction in this means a smaller supply of potential mothers, while the acceleration of outward movement will remove more of them, as the exodus from London is concentrated in ages up to the $40 \mathrm{~s}$. As regards London's gains from international migration, they are mainly of people in their 20s and 30s, so a lowering of these numbers in the new projections also directly affects the size of the main child-bearing groups.

\section{'The changes in London's expected migration between the 2014- and 2016-based projections play a key role in the reduction in the capital's expected population growth; so how much confidence can be placed in the new figures?'}

\footnotetext{
What this means, of course, is that London's projected number of births is sensitive - albeit to a much smaller degree than how accurate the fertility assumptions prove to be - to whether or not the two sets of migration assumptions turn out to be correct. The rest of this article focuses on these.

Looking first at international migration, the main change from the 2014-based series is again a national
}

one. ${ }^{4}$ The ONS is now assuming that the UK's longterm level of net immigration from abroad (applying from year 7 of the projection period onwards) will be 165,000 rather than 185,000 , with the preceding six years involving a set of rather sharp downward steps from the 335,000 estimated for 2015-16. In addition, the new projections incorporate some methodological developments, most importantly one that aims to provide a more accurate estimate of emigration. The combined outcome for London is that its long-term net gain from abroad is now set at 67,600 a year, which represents a substantial drop from the 114,225 estimated for 2015-16.

As regards migration between London and the rest of the UK, what explains the acceleration in the capital's net exodus between the 2014- and 2016based projections shown in Table 2? The answer lies in the ONS basing its assumptions on the average of the migration rates observed over the latest five years. ${ }^{5}$ Thus for the latest projections this refers to the period from mid-2011 to mid-2016, whereas for the 2014-based set the reference period was mid-2009 to mid-2014. The reason why this shift in the window makes such a big difference is that London's within-UK migration is rather sensitive to the state of the economy, and the new window is now two years further away from the 2008-09 recession.

As documented by much research, most recently by a report on migration in the Wider South East commissioned by the East of England Local Government Association (EELGA), ${ }^{6}$ London's net exodus is at its lowest point during a national downturn and then picks up again during the subsequent recovery. While seemingly paradoxical, this pattern arises mainly from the fact that those intending to move out of the capital are less able and/or willing to do so when their jobs may be threatened and the housing market is in the doldrums. A contributory factor is that London's inflow does not fluctuate as much because it is dominated by young adults and especially recent graduates, whose numbers nationally do not alter much in the short term and who regard London as the best bet for jobs, even in a recession.

These changes in London's expected migration between the 2014- and 2016-based projections play a key role in the reduction in the capital's expected population growth, as seen in Table 2; so how much confidence can be placed in the new figures?

It is very difficult to give a definitive answer in relation to international migration, because this has become the most unpredictable component of population change - taking over from fertility, which once provided the major upsets and even now remains relatively volatile, as shown above. This uncertainty arises partly because, despite the ONS's recent improvements in its monitoring, the latter is still heavily reliant on small samples of data derived 


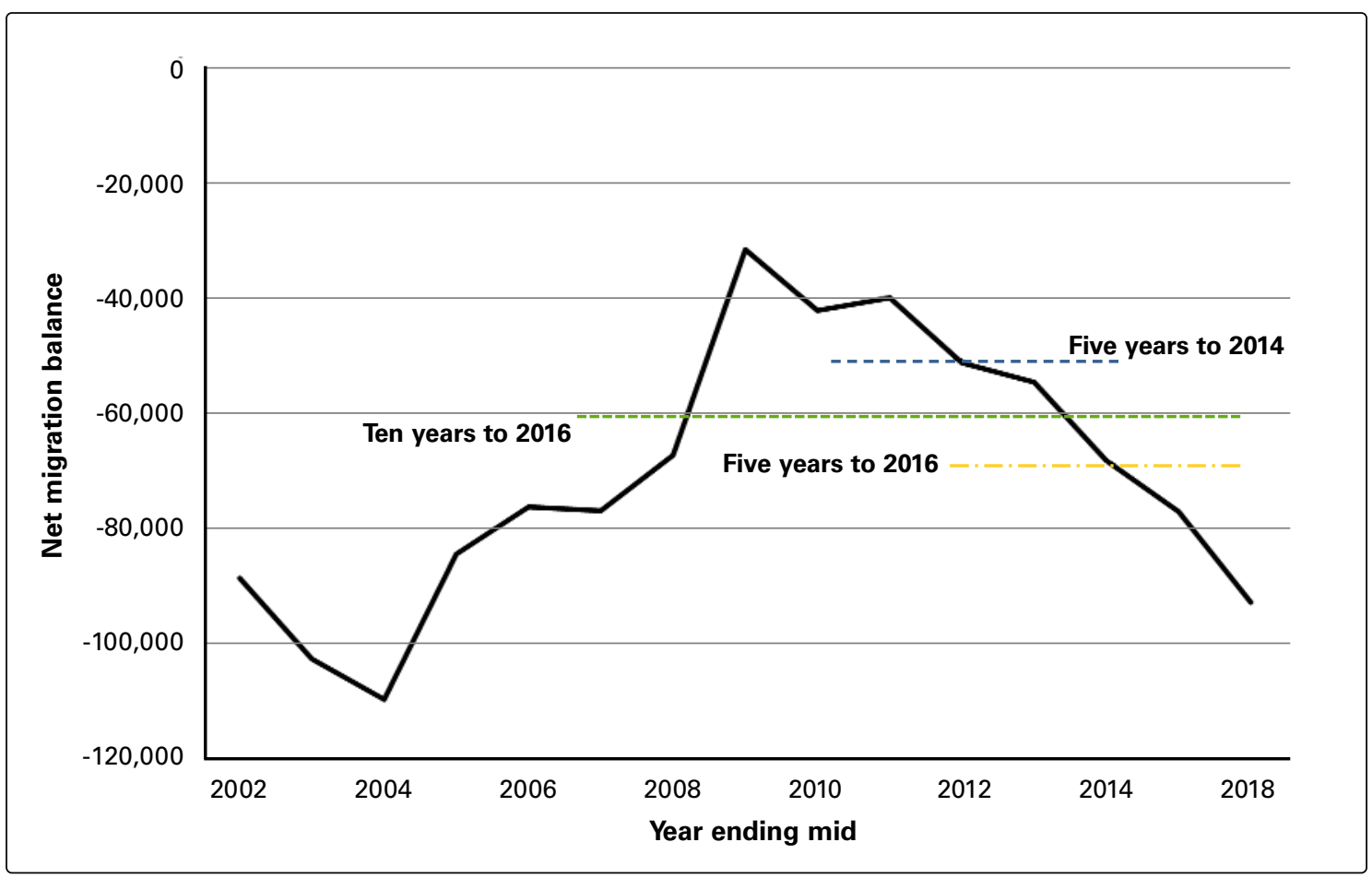

Fig. 1 London's net migration balance with the rest of the UK, 2001-16, with annual averages for selected periods

from the International Passenger Survey, resulting in big swings in annual numbers and wide confidence ranges. But it is also arises from substantial real fluctuations that reflect changes over time in labour demand and the nature and effectiveness of admissions policy, along with variation from year to year in the scale of asylum-seeking.

\section{'Any reduction in London's assumed net gain from abroad - as indicated by comparing the 2014- and 2016-based projections - would be expected to reduce the scale of 'displacement' and lead to less pressure for overspill out of London, but this is not allowed for in the projection process'}

Perhaps the most that can be said at this juncture is that the ONS's continued practice of scaling down the numbers of immigrants over the first six years of the projection to a long-term level well below that observed in the immediate run-up to the base year has thus far proved to be a long way off the mark, but perhaps things will be different this time with Brexit.

Turning to London's migration exchanges with the rest of the UK, there are two main worries about the ONS's approach. One concerns the projections methodology not including any direct link between within-UK and international migration, despite the fact that there is now much evidence of a correlation between the two. As documented in the EELGA report, ${ }^{6}$ it is not just the state of the economy that affects the net exodus from London but also changes in the volume of the capital's net gain from abroad: when the latter rises, so does London's net loss to the rest of UK in a type of 'displacement' process. As a result, any reduction in London's assumed net gain from abroad - as indicated by comparing the 2014- and 2016-based projections - would be expected to reduce the scale of this effect and lead to less pressure for overspill out of London, but this is not allowed for in the projection process.

The other issue relates to the ONS's practice of averaging the rates for the latest five years of records to form the basis for the next 25 years. As mentioned above, London's net out-migration fluctuates considerably over time, so the choice of calibration period is crucial.

This is illustrated in Fig. 1, which shows the net exodus peaking at some 110,000 in 2003/04, then reducing fairly steadily to 32,000 at the height of the recession in 2008/09 and subsequently moving back towards the earlier peak. The horizontal lines 


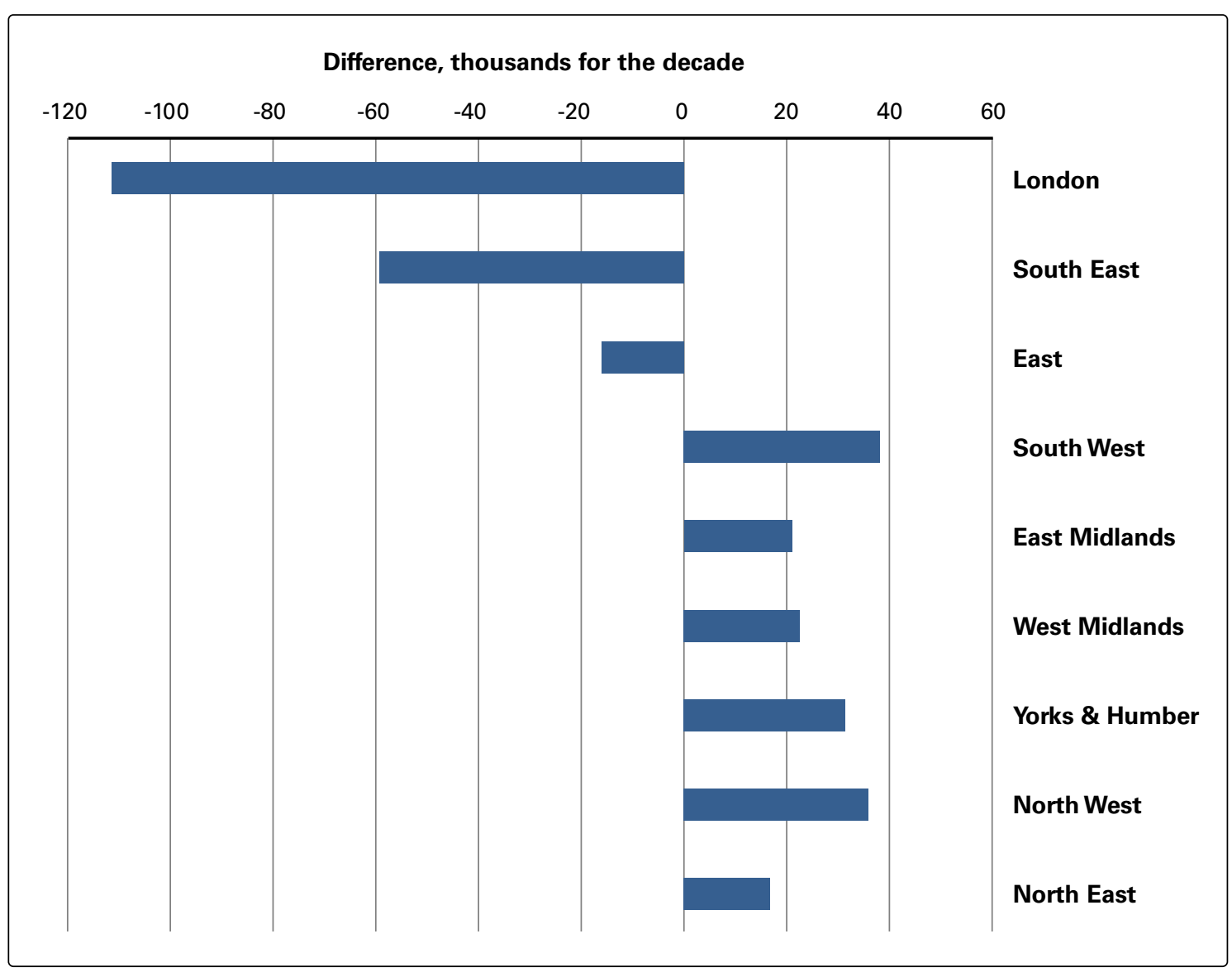

Fig. 2 Difference between 2014- and 2016-based projections of within-UK migration balance for 2016-26, by region

indicate the average annual volume for alternative calibration periods. That for the five years used for the 2016-based projections comes to 69,200, whereas that for the previous set was 51,600 . By contrast, if the reference period was extended to ten years which is the length of time that the Greater London Authority ${ }^{2}$ uses as the basis for its 'central projection' (the others being five and 15 years) - then the average annual rate lies between these two, at an average annual net loss of 60,600 to the rest of the UK.

The fact that moving the five-year window forward by just two years can alter the ONS's projection of London's net exodus by as much as 17,600 a year makes a strong case for adopting a longer period that spans short-term economic oscillations more fully. Nevertheless, in the present case the five-year average to 2016 looks more plausible than the fiveyear one to 2014, in that it runs pretty close to the average of the first ten years from 2001, with the annual net loss being higher than the 69,200 mark until 2006-07, and then lower than it for the next four years. But clearly, in principle, a longer calibration period would inspire more confidence.

Finally, and leading on from this, the raising of London's net out-migration to the rest of the UK between the two projections has impacts on the net balances of the rest of the country. The difference between the 2014- and 2016-based projections for the net within-UK migration balances for each English region is shown in Fig. 2, with the total 2016-26 difference for London amounting to 111,000 , as previously indicated in Table 2 . What is particularly noteworthy from this chart is that the impact of this projected greater out-migration from the capital is not being felt by the two adjacent regions of the South East and East, at least not in these net terms - indeed, these two regions are, like London, also expected to have a less positive migration balance than projected for this decade by the 2014-based set. Instead, it is the rest of the country that sees faster population growth from this source in the 2016-based projections, with all the other regions taking a share of the extra net out-migration from the three regions of the Wider South East.

But will this turn out to be the case? Again, the issue revolves around the use of the five-year calibration period, as it did for anticipating the future level of London's overall net exodus; but the verdict here is rather different. This is because the exodus's 
geographical impact varies through the business cycle, even between the early and later stages of a recovery.

As documented in the EELGA report, ${ }^{6}$ the initial impact of a London-led recovery is obviously experienced by the capital itself and the areas immediately surrounding it, but as pressures build up there, then the effects are felt further afield - a process most commonly spoken of in terms of the 'house-price ripple'. This moves out across the country, so cannot be expected to remain in place until 2026, let alone 2041. It thus reinforces the case for basing sub-national population projections on a longer reference period, but in the meantime it also means that caution must be exercised in using these latest population projections as a basis for informing policy-making and planning decisions.

\section{'As regards within-UK migration, the research evidence suggests that the scale of London's net exodus indicated by the 2016- based projections may be closer to the likely outturn than that of the 2014-based set, but the projections of the geographical distribution of the higher level of gain for the rest of the country are unlikely to be so robust'}

In a nutshell, as regards within-UK migration, the research evidence suggests that the scale of London's net exodus indicated by the 2016-based projections may be closer to the likely outturn than that of the 2014-based set, where the reference period was dominated by the immediate aftermath of recession, but the projections of the geographical distribution of the higher level of gain for the rest of the country are unlikely to be so robust. There is, of course, no substitute for closely monitoring events as they unfold, as is also true for mortality, fertility and international migration, but the adoption of a longer calibration period for within-UK migration would serve to reduce the extent to which the subnational projections need adjusting between each two-yearly round and thereby provide a more robust basis for planning.

- Tony Champion is Emeritus Professor of Population Geography at Newcastle University. The views expressed are personal.
Notes

1 Subnational Population Projections for England: 2016based. Statistical Bulletin. Office for National Statistics, May 2018. www.ons.gov.uk/releases/

subnationalpopulationprojectionsforengland2016based projections

2 The London Plan: The Spatial Development Strategy for Greater London. Draft for Public Consultation. Mayor of London. Greater London Authority, Dec. 2017. www.london.gov.uk/what-we-do/planning/londonplan/new-london-plan

3 Changing Trends in Mortality in England and Wales: 1990 to 2017 (Experimental Statistics). Statistical Article. Office for National Statistics, Jun. 2018.

www.ons.gov.uk/peoplepopulationandcommunity/ birthsdeathsandmarriages/deaths/articles/

changingtrendsinmortalityinenglandandwales1990to2017/ experimentalstatistics. See also CWhite: 'Grinding to a halt. Is the growth in life expectancy coming to an end?' Office for National Statistics Blog, 18 Jun. 2018. https://blog.ons.gov.uk/2018/06/18/grinding-to-a-halt-islife-expectancy-coming-to-an-end/

4 National Population Projections: 2016-based Projections, Methodology. Compendium. Office for National Statistics, Oct. 2017. www.ons.gov.uk/peoplepopulationandcommunity/ populationandmigration/populationprojections/ compendium/nationalpopulationprojections/ 2016basedprojections

5 2016-based Subnational Population Projections for England: Changes to Methodology and Source Data. Statistical Article. Office for National Statistics, Jan. 2018. www.ons.gov.uk/peoplepopulationandcommunity/ populationandmigration/populationprojections/articles/ 2016basedsubnationalpopulationprojectionsforengland changestomethodologyandsourcedata/2018-01-19

6 I Gordon, T Champion, N McDonald and C Whitehead: Review of Research on Migration Influences and Implications for Population Dynamics in the Wider South East. Report for the East of England Local Government Association, Dec. 2017. http://lselondonhousing.org/wp-content/uploads/2018/ 01/EELGA-MIgration-Project_Main-Report_plusExec.pdf 